\title{
Possível reconfiguração dos modelos educacionais pós-pandemia
}

BERNARDETE A. GATTII

\section{Considerações iniciais}

$\mathrm{P}$ ENSAR reconfigurações na educação no pós-pandemia implica refletir sobre as possibilidades e limites para isso, tanto no âmbito da educação básica, considerando seus diversos níveis de ensino, como no âmbito da educação superior, com seus diferenciais institucionais e curriculares.

Essa reflexão necessariamente incorpora considerar se as situações vividas na pandemia provocada pelo Covid-19, que hoje assola o mundo, provocarão de fato alterações substantivas quer do ponto de vista econômico, quer do cultural ou do social. Ou seja, se seus efeitos serão na direção de transformações nas formas de conceber a vida, os valores, de relacionar-se, trabalhar, produzir, consumir e educar, ou, na direção de uma volta às condições anteriores ao evento da pandemia retomando-se os mesmos padrões já anteriormente consolidados, como que esquecidos das quarentenas, da quase paralisação do sistema produtivo e do comércio, dos dilemas na saúde, das soluções encontradas para o momento, das alternativas criadas e das dificuldades para as relações interpessoais tão caras na nossa convivência social. Entre esses dois extremos pode-se considerar a emergência de trajetórias, por assim dizer, intermediárias, com mudanças esparsas em alguns segmentos da vida humana, a qual é, lembremos, intrinsecamente social. Somos orgânicos, somos seres gregários e necessitamos uns dos outros, como também da natureza, para nossa sobrevivência. Somos parte da natureza e construímos uma sociedade que avançou em conquistas sociais, científicas, em habitação, alimentação e saúde, com fundamentos propiciados pela expansão da educação, em relação dialética com os conhecimentos consolidados por consenso e pela demonstração de sua plausibilidade. Também pela preservação de valores e atitudes que vêm contribuindo para ampliar os direitos humanos e a luta pelo respeito ao meio ambiente, mesmo considerando as desigualdades e as diferenças de posições que geraram e ainda geram muitos conflitos de interesses e a presença de desequilíbrios.

Nos dias que correm a questão é: desafiados por um vírus, que alterou aspectos substantivos de nossa vida em sociedade, obrigando-nos ao isolamento e a incorporar hábitos defensivos de higiene e de precaução quase extrema nos contatos, seremos capazes de ampliar nossos horizontes de consciência social? 
Vislumbrar o que nos assombrou no enfrentamento dessa situação, quais foram os empecilhos a vencer, o que tivemos que suportar e superar nessa situação, perceber o que se precisou fazer e se fez de diferente, que alternativas foram criadas para manter a vida, as relações e a sociedade, e assim, projetar o que é necessário mudar estruturalmente para garantia da vida com dignidade para todos? Tomará corpo, em agenda de primeira linha, repensar o bem comum diante de tanta desigualdade aviltante revelada, da incapacidade de tantos, especialmente de gestores públicos ou privados, de perceberem o todo da situação? Tomará corpo a importância de reconfigurar aspectos cruciais para essa civilização como a educação das novas gerações, a saúde coletiva, o direito à moradia, entre outros que dignificam a condição humana? Já vem sendo posto que a lógica atual do mercado não vai ajudar, que interesses particulares também não, e que a competitividade exacerbada pode ser destruidora de possibilidades de construção de equidade social. Assim, fica a grande questão: com quanto de compreensão ampla do bem comum, do bem público e do bem-estar social, bem como de formas de cooperação poderemos contar?

As dificuldades da situação que enfrentamos encontram-se nas relações entre a preservação da vida e as necessidades sociais tão preciosas a nós humanos, seres gregários que somos, bem como as dificuldade relativas ao trabalho, à economia e à sustentabilidade das instituições.

\section{Instituições educacionais: orientações e redes escolares}

Tanto a educação básica como a superior, por meio de suas escolas e instituições, públicas ou privadas, se inserem nesse movimento e nessa situação pandêmica, e não estão isentas dos conflitos, das disputas de poder, de interesses diversos e do jogo econômico, no bojo, também, das desigualdades institucionais e entre redes de ensino.

Sendo o Brasil uma federação, com cada ente federado tendo suas atribuições específicas em situação de paridade (nível federal, estadual e municipal), como consolidou nossa Constituição Federal de 1988 (Brasil, 1988), a integração de políticas e propostas educacionais depende de articulações entre os poderes para, coordenadamente construirem-se orientações coerentes e bem fundamentadas, ações integradas e apoios diversos. Nesse ponto tivemos dificuldades várias mesmo antes do evento da necessidade do isolamento social, o que se agravou com essa emergência. As atribuições de cada nível são diferentes e estão definidas pela Lei de Diretrizes e Bases da Educação Nacional, Lei n.9394/96 (Brasil, 1996). O Ensino Superior é incumbência preferencial da União, e cabe ao Conselho Nacional de Educação (CNE) fixar normas diversas, orientações e suas diretrizes curriculares. A base curricular nacional para a educação básica também é atribuição do CNE mas as estruturação, gestão, orientação e execução das ações educativas das redes escolares desse nível educacional são atribuições de estados e municípios, prioritariamente, os quais, a partir das diretrizes básicas nacionais, definem seus próprios currículos e o modo do funcionamento de suas 
escolas: características da direção escolar, incorporação de docentes, carreiras, suportes etc. Temos um mosaico complexo e diversificado no que se refere a oferta e dinâmicas da educação básica, como também de políticas de ação.

Várias medidas e orientações advieram, nesse período de pandemia que atravessamos, tanto do Ministério da Educação como do Conselho Nacional de Educação para o funcionamento das instituições educadoras na emergência das condições de isolamento social impostas pela situação social criada por essa pandemia. Estados e municípios também tomaram suas decisões. No que diz respeito à educação superior normas mais detalhadas foram exaradas em nível federal, mas também recentemente publicaram-se orientações do Conselho Nacional de Educação (Brasil, 2020) em que, respeitando a autonomia das escolas e dos sistemas de ensino, são apresentadas sugestões relativamente detalhadas para realização de atividades presenciais e não presenciais na educação básica, quanto à reorganização dos calendários escolares e o replanejamento curricular no contexto da atual pandemia. É um parecer e pode ser utilizado como baliza por todos os entes federados que assim quiserem.

\section{A educação básica neste cenário}

Vou abordar mais especificamente questões ligadas à educação básica na conjuntura atual trazendo aspectos que tocam à gestão, e, posteriormente, trarei as questões de preservação da saúde e das aprendizagens dos estudantes de todas as idades, sobre professores e gestores, aspectos curriculares e os relacionais e socioemocionais envolvidos no processo de isolamento e retorno presencial nas escolas. Trata-se na educação básica de mais de 48 milhões de alunos, 81\% vinculados a escolas públicas (Anuário, 2019).

Durante a pandemia que atravessamos, no que respeita a esse nível educacional, alguns entendimentos foram feitos entre estados e municípios, por intermediação do Conselho de Secretários Estaduais de Educação (Consed) e da União Nacional de Dirigentes Municipais de Educação (Undime) e suas regionais. Visou-se o desenvolvimento de soluções considerando adequações de oferta escolar em virtude do advento da pandemia levando em conta as situações econômico-sociais-culturais diversas que se mostram na extensão deste país, e as desigualdades que se tornaram evidentes nesse contexto. Secretarias de educação, municipais e estaduais, conselhos estaduais e municipais também elaboraram orientações para esse período emergencial em articulação com as respectivas secretarias de educação no que respeita a calendário, educação em modalidade remota e currículos. Aqui já se coloca a questão das perspectivas de diferentes agentes e níveis de gestão que tomaram decisões ad-hoc, embora de modo geral atentos às orientações das autoridades da saúde. Mas, do ponto de vista das governanças regionais e locais, sem uma articulação mais geral de governo, houve muita disparidade entre estados e municípios nas tomadas de decisões políticas relativas à saúde pública, com certo desencontro de ações, o que não deixou de causar agravantes para a situação geral social e educacional. No específico 
da educação básica, em função das articulações citadas manteve-se a proposta de educação em forma remota, com variações nas propostas, e com vários percalços. Caminhos variados foram encontrados com a utilização de diversas plataformas educacionais, com utilização da internet, solução que se mostrou, na situação, acessível a muitas redes, escolas e seus estudantes, mas não para todos. Em outras circunstâncias também se recorreu ao envio de material impresso aos alunos, com possibilidade de retorno à escola de atividades e tarefas propostas. Orientações a pais fizeram parte da ação de algumas propostas de redes de educação básica, muito especialmente no referente a crianças pequenas - creches e pré-escolas. Observaram-se também situações em que as atividades educacionais foram simplesmente paralisadas por injunções diversas (Undime et al., 2020; Villas Bôas; Unbehaum, 2020).

Com esse contexto constata-se a heterogeneidade de situações experimentadas pelas crianças, adolescentes e jovens matriculados na educação básica e suas famílias.

\section{Olhando para a realidade educacional}

A situação pandêmica obrigou crianças, adolescentes e jovens a mudarem seus hábitos relacionais e de movimento, a estudarem de modo remoto, alguns com boas condições, com acesso à internet, com os suportes necessários (computador, tablet ou celulares), mas muitos não dispondo dessas facilidades, ou dispondo com restrições (por exemplo, não disposição de rede de internet ou de computador ou outro suporte, posse de celulares pré-pagos com pouco acesso a redes; um só celular na família etc.), contando ainda aqueles sem condição alguma para uso dos suportes tecnológicos escolhidos para suprir o modo presencial. Agregue-se a essas condições o grande contingente de alunos que não puderam contar com apoio mais efetivo dos pais por seu nível educacional, ou por trabalharem em setores prioritários durante o isolamento, ou por outros motivos. Ainda, evidenciou-se situação de alunos dependentes de redes educacionais que elas próprias não tinham condições de oferta remota de seus currículos. Também, pendências curriculares ficaram em suspensão, como as atividades práticas, as de laboratórios, as de campo e os estágios na educação média profissional. Questões se mostraram como dificuldades, como as condições e formação dos docentes para trabalho de educação escolar em modo remoto e para uso de mídias, para o desenvolvimento de formas de envolvimento ativo dos estudantes, desenvolvimento de atividades compartilhadas, e mesmo a avaliação do desempenho dos alunos. Muitas dúvidas e preocupações existem relativas ao atendimento às crianças pequenas que frequentavam creches, as da pré-escola, $\mathrm{e}$ as em processo de alfabetização, considerando as necessidades e condições dessas faixas etárias, e também a falta de metodologias a distância suficientemente estudadas e consolidadas para esses níveis educativos, lembrando os limites de uso por crianças pequenas de aparelhos receptores. Considere-se a situação de vulnerabilidade social em que muitas dessas crianças estão. Não há evidências de 
boas soluções nessa emergência para a ampla população de crianças vinculadas às escolas públicas. $\mathrm{O}$ atendimento daqueles que demandam atenção especial também ficou com precárias alternativas.

Se algumas soluções foram encontradas para a manutenção do vínculo de estudantes com a instituição de ensino, seus professores e colegas, de outro lado verificaram-se dificuldades ponderáveis: o estudo e aprendizagem de conteúdos curriculares novos em modo de isolamento, com apoios delimitados pela situação remota, dificuldades de atenção e concentração, o estresse de alunos pela situação do isolamento, por excesso de conteúdos emitidos ou de tempo dedicado diante de tela de computador ou outro aparelho digital, trocas relativizadas pelo esforço comunicativo demandado, falta do calor dos laços presenciais, entre outras situações, o estresse dos professores pela exigência rápida de novas performances, de preparação de aulas virtuais demandando mudanças em perspectivas didáticas, esforço de manejo técnico de instrumentos não habituais em sua rotina de trabalho.

É preciso reconhecer que esse cenário provoca efeitos emocionais para todos, em níveis variados, considerando ainda que há ambiguidades na compreensão da situação de isolamento e da própria doença que é foco da pandemia; há o receio do contágio, mais ou menos consciente; a angústia do isolamento em relação a colegas e amigos; ansiedades relativas a compreensão de conteúdos escolares e desempenho; sensação de pressão, de cobrança, e aparecimento de estafa pelo esforço de atenção necessário e tempo diante de vídeo, gerando até sentimento de rejeição aos estudos pelo limite dos contatos possíveis (Conjuve, 2020; Instituto Península, 2020).

\section{$O$ retorno às escolas: a transição}

O retorno às escolas será importante uma vez que aspectos de sociabilidade humana e condições de aprendizagem de crianças e adolescentes devem ser considerados. Esses aspectos ligados à natureza psicológica, cognitiva e emocional das pessoas, constituintes do próprio desenvolvimento humano propiciado por atividades coletivas e conjuntas, face a face, pelo poder tocar, manejar objetos, utilizar olfato e gosto em situações de presença de outros, com trocas de experiências em realidades, experimentar movimentos no coletivo e na natureza, compartilhar expressões sutis, formar valores de vida com a experiência corporal, com sua força e fragilidades, entender os limites de nosso físico e os limites que formam a moral na delicadeza necessária nos contatos com os iguais e o respeito às diversidades, enfim, tudo o que constitui-se na vida em sociedade e que constituiem-se em possibilidades de preenchimento das necessidades emocionais próprias ao ser humano chamam pela sociabilidade presencial, pela possibilidade de estar com, e não apenas de se pensar ou sentir com... (Maturana, 2001; Maturana; Varella, 2001). O papel relevante da presença, atitudes e ações de adultos em situações de aprendizagens com crianças e jovens, e nas condições de socialização e desenvolvimento, já foi suficientemente destacado por teorias fortes do desenvolvimento humano e da neuropsicologia (Wallon, 1973; 2007; 
2008; Piaget, 1971; 1978; 1986; Vigotsky, 2007; 2003; Bruner, 1998; Wenger, 1988; Paula et al., 2006; Lent, 2019). Do ponto de vista psicossociológico a escola representa para os alunos não só um lugar para estudos, mas um lugar para encontros, um lugar para socializar, cultivar amizades, confrontar-se, definir sua identidade. A escola, como um coletivo, é o ambiente que permite às crianças a entrada em um primeiro ensaio de vida pública, de certo tipo de cidadania, fora do círculo familiar. Voltar ao convívio em ambiências escolares e de aprendizagem será praticamente inevitável assim que as condições permitirem. A ansiedade de pessoas, adultas, jovens ou crianças pelas possibilidades de contato pessoal vem sendo analisada em vários estudos já disponíveis. O problema de olhar para o retorno escolar nas condições experimentadas no período de isolamento social não é só do Brasil, mas de todos os países (Reimers; Schleicher, 2020; CTE-IRB/Iede, 2020).

A pergunta hoje é: em que condições e com quais dinâmicas escolares voltar à escolaridade presencial? Essa é uma questão para a qual não se dispõe de soluções mágicas, ou soluções definitivas, ou sequer uma única possível solução dadas as diferenças contextuais e sociais no país e as desigualdade da oferta educacional nesse período e das possibilidades também diferentes de condições de estudo evidenciado pelas crianças e adolescentes na situação remota. Deve-se lembrar sobretudo de que atividades pré-escolares e de alfabetização foram as mais prejudicadas pela inexistência de propostas adequadas para esta situação. A quase falta de discussão que se verifica sobre esse nível de escolaridade testemunha o quanto "os que têm voz" deixam de lado questão que é esquecida e bem incômoda, sob vários aspectos. Mas o desenvolvimento integral nessa fase da vida é insubstituível, é vital.

\section{Vetores saudáveis}

Dado que, como discutimos, seres humanos têm características gregárias e que historicamente construíram estratégias de sobrevivência e cultura no coletivo, isolamento não é a ambiência mais propícia às nossas formas de vivência e de aprendizagens, considerando que as aprendizagens humanas não são somente puramente cognitivas e que criamos necessidades afetivo-sociais que importam. $\mathrm{O}$ isolamento representou uma situação de privação. Uma ambiência de acolhimento cuidadoso de alunos, educadores e funcionários será necessária em direção a um bem-estar coletivo, dadas as devidas garantias de preservação da saúde de todos. Nesse sentido, um esforço de gestão em modo participativo será demandado para a preparação dos próprios gestores, de educadores e funcionários para o retorno e o recebimento dos alunos, lembrando-se de que tanto alunos como os trabalhadores da educação podem ter tido experiências com a doença - em família por exemplo, e, mesmo perdas de pessoas importantes em suas vidas. Perdas têm efeitos pessoais consideráveis ainda mais nessa situação com tantos impedimentos.

O retorno dos contatos sociais escolares, ao mesmo tempo que se apresenta como um desejo, também gera certo grau de insegurança e medos. Isso tem que 
ser considerado. Daí o preparo psicológico dos vários grupos envolvidos com a escolarização, criando abertura para trocas, conversas, sobre como se sentiram com as novas ações que lhes foram exigidas no período de isolamento: uso de redes, de mídias diversas, as novas propostas, as facilidades, necessidades ou dificuldades que perceberam, aprendizagens diversas, ganhos que avaliam que tiveram ou não.

Dado o contexto vivido, vetor relevante é a criação de ambiente de serenidade entre os educadores em relação aos ajustes físicos, infraestruturais, curriculares e para a recepção das crianças, adolescentes e jovens considerando aqui as diferenças de desenvolvimento biopsicossociais entre eles e as diferentes oportunidades que tiveram de estudo ou não, de terem tido apoios ou não. Isso implica criar estímulo entre os educadores para engajar-se nesse processo de recuperação das condições de aprendizagem do alunado nas novas condições. Os pais precisam ser considerados e contatos coletivos ou individuais remotos podem favorecer trocas de informações e compreensões sobre aspectos do retorno e apoios para as novas condições. Será necessário criar com eles laços de confiança e a compreensão sobre a nova temporalidade que deverá ser considerada na educação escolar e nas aprendizagens correspondentes, com a perspectiva de valores que deverão ser ressignificados nos tempos a vir.

O vetor mais saudável, determinante nessa situação, é a capacidade humana de utilizar o bom senso e saber buscar equilíbrio nas decisões, ações e relações. Será necessário ter sensibilidade para a diversidade de situações enfrentadas por todos os envolvidos quanto ao que se passou nas tentativas de manutenção das atividades escolares e das aprendizagens, efetivadas ou não, nesse período transitivo agudo da pandemia pela Covid-19. Bom senso e equilíbrio na compreensão do vivido, com a maior objetividade possível, e nas decisões de futuro, com apoio tanto em conhecimentos disponíveis sobre as possibilidades de manutenção da saúde de todos os envolvidos como em conhecimentos sobre situações específicas em variados nichos sociais e in loco, além dos conhecimentos psicopedagógicos inerentes ao trabalho escolar e ao desenvolvimento sociocognitivo e emocional de crianças, adolescentes e jovens. Cuidar de não cair no risco de tomar decisões por razões de modismos, de custos ou lucro.

Há vários outros aspectos a considerar no retorno às aulas presenciais e o vetor-chave aqui é planejamento flexível e local. A data e as formas de retorno, quase todos já estamos conscientes disso, são questão que deve considerar os dados de avanço/retrocesso nas contaminações pela Covid-19 e seus efeitos. Evidente, também, é que condições básicas de infraestrutura e de higiene, por razões científicas, deverão ser garantidas nos ambientes das escolas. Para tanto existem protocolos definidos que estipulam as ações necessárias. Há também discussões para o planejamento da volta dos alunos por grupos. Estados e municípios, bem como escolas particulares debruçam-se sobre várias possibilidades buscando as que garantam menor risco para a saúde de alunos e profissionais que trabalham na escola. A maior dúvida centra-se sobre a decisão de por qual faixa etária começar, mas há grande preocupação com a volta das crianças peque- 
nas e as do primeiro ciclo do Ensino Fundamental. Como ajudá-las a entender que de início não poderão se aproximar muito de colegas e professores(as) é questão que se coloca, entre outras. Nesse momento há municípios que são os responsáveis por esse nível educacional, que já tomaram a decisão de permanecer até ao final deste ano com o trabalho escolar remoto. Nesse ponto, variadas soluções são possibilidades dependendo de condições regionais ou locais.

No escalonamento da frequência dos alunos, que será necessário para garantir distanciamento físico entre estudantes, soluções pedagógico-didáticas deverão ser criadas. Para os gestores o problema será o aumento de turmas por professor ou a contratação de novos docentes ou a construção de uma logística que respeite os contratos de trabalho de docentes e especialistas. Acima de tudo, o respeito ao limite humano para o trabalho com e dos alunos, presencial/ virtual/remoto, para o planejamento e execução das ações pedagógicas, tempo demandado e esforço de ambos, devem ser considerados.

A institucionalização, nesse período de transição, do que se está chamando de ensino híbrido na educação básica - em parte presencial e em parte remoto também deverá considerar os fatores aqui elencados e ser resolvida com soluções pedagógicas bem fundamentadas e com materiais adequadamente elaborados e colocados à disposição de todos, em formatos que realmente todos os alunos tenham acesso por igual. $\mathrm{O}$ uso de diferentes plataformas e materiais midiáticos, impressos ou outros, será bem-vindo mas essa utilização deve basear-se nas condições do alunado e de suas possibilidades de acompanhamento real do currículo - limites dos meios e limites humanos -, considerando as condições socioculturais de crianças e adolescentes e seus determinantes físicos, fisiológicos e emocionais - capacidade de atenção, motivação, tempo de dedicação exigido, estafa etc. Não se devem extrapolar condições de um adulto para crianças e adolescentes.

Ponto fundamental para as aprendizagens serão as escolhas sobre o que é essencial que os alunos aprendam e por quais caminhos de aprendizagem. Esse ponto será desafio para redes, escolas e professores. Tempos e espaços de aprendizagem deverão ser reconsiderados. O tempo de aprendizagem escolar precisará ter foco no que é realmente importante e nas formas que garantam desenvolvimento cognitivo flexível, permitindo a construção criativa de conceitos, de problematização e de busca de outros ou novos conhecimentos. Detalhe de detalhe não cabe nessa temporalidade nova que está sendo colocada no retorno à escola, seja pela formação presencial, seja por uma parte remota. Haverá necessidade de esforço para repensar aspectos ligados aos conteúdos e às didáticas, buscando formas ativas e participativas de construção de mediações cognitivas.

Será importante ponderar sobre o que foi realmente propiciado pela escola e professores durante o período de recolhimento, buscando evidências de aprendizagens construídas de fato, com realismo. Meios para tanto serão diálogos francos com os grupos de alunos, diálogos abertos sem ameaças ou pressão, avaliações de cunho mais qualitativo, avaliações-minuto, e eventualmente, um 
pouco mais tarde, algum tipo de prova apenas com valor diagnóstico. O uso desse instrumento deve ser precedido do acolhimento aos alunos, dos diálogos e outros tipos de demonstração de conhecimentos pelos alunos, e nunca nos primeiros contatos presenciais. A partir desse conjunto de ações, e à luz do currículo, é que se podem escolher com mais pertinência os temas e ações fundamentais em cada área de conhecimento e disciplinas, para cada nível e ano escolar. Importante selecionar o essencial, como já apontado. Poderá ser necessária a retomada de aspectos que deveriam ter sido dominados, mas que, para os quais, pelas circunstâncias do isolamento e do trabalho do aluno em sua situação distanciada de professores e colegas, houve dificuldade no trato de alguns dos conteúdos disciplinares. Isso deve ser considerado e demandará intenso trabalho de gestores, coordenadores pedagógicos e docentes. Cooperação e participação de todos, inclusive por parte dos alunos, serão necessárias.

Todos esses aspectos levantados precisarão de suportes de diferentes naturezas para que se realizem. O abrir-se para a flexibilidade nos planejamentos e para a criação de diferentes possibilidades quanto às dinâmicas pedagógicas será ponto forte. O principal vetor relevante aqui é o desencadeamento de processos de formação contínua da equipe gestora e dos professores considerando as necessidades em cada escola. O objetivo será alavancar as aprendizagens de todos e não acionar comportamentos que propiciam seletividade e frustrações. Em todas as ações será desejável mostrar objetividade sensível nos ajustes e nas formações a serem propiciadas. Formatos participativos deverão ser privilegiados. Atitudes de compartilhamento, escuta, abertura à participação, consolidação coletiva de consensos, busca do mais simples e do essencial, serão relevantes à construção segura de possibilidades formativas para todos os responsáveis pela criação de ambiências de aprendizagem saudáveis e motivadoras para os alunos.

\section{Futuro próximo}

Enseja-se um novo modo de lidar nas escolas com o ensino e a educação das novas gerações que aí estarão inseridas. Deixar velhos hábitos, buscar novos sentidos para a educação escolar e novos caminhos. Mudar horizontes e não reproduzir mais do mesmo e lamentar perdas em relação a um modelo escolar que pede por mudanças: um modelo com visões apenas imediatistas e competitivas. É a oportunidade que se espera possa ser utilizada para dar novos formatos e significado à educação na escola básica não só nessa transição da pandemia para a volta às escolas, mas para o futuro. Também, pensar em perpetuar nas escolas $\mathrm{o}$ chamado ensino híbrido, como uma panaceia, deve ser ponderado com cautela em face do que já foi colocado aqui sobre as condições referentes ao desenvolvimento humano em sua integralidade e as condições socioeconômicas dos estudantes. É preciso considerar que mídias também podem ser utilizadas de modo tão passivo, ou até mais, quanto as aulas tradicionais. O que parece mais efetivo é a integração no trabalho pedagógico dentro dos espaços escolares daquilo que as diferentes mídias podem oferecer à educação, com mediações motivadoras 
dos professores, criando nova distribuição dos tempos para as aprendizagens e utilizando espaços variados, com a utilização de dinâmicas didáticas em que alunos sejam protagonistas ativos.

O aprendido quanto ao ensinar e educar, sob diferentes aspectos, com o isolamento social e na transição que se está construindo, poderá consolidar-se em mudanças efetivas para que se configurem em novas formas de formação escolar? O ponto forte nessa questão vincula-se a qual probabilidade teremos de pensar qualidade da educação em outro gabarito, com novos valores. Esse parece ser o desafio que nos está colocado, no que se refere tanto às gestões como às dinâmicas curriculares e pedagógicas no futuro próximo. É bom considerar que em situação sem o evento da pandemia já se percebia o quanto o trabalho escolar vinha perdendo significado para adolescentes e jovens. Carvalho (2017, p.1025), discutindo o que chama de crise das escolas, chama a atenção para "um aspecto que costuma permanecer oculto na maior parte dos discursos críticos acerca da escolarização contemporânea: o esvanecimento do sentido político e existencial da experiência escolar". Político no sentido do humano-social e ético, e existencial no sentido de ser um "potencial lugar de experiências; como um palco para encontros intergeracionais mediados pelo diálogo com um conjunto de objetos e práticas culturais". Lembra a importância de a educação vincular-se a um sentido ético, de formação do espírito. Formar pessoas com autonomia ética. Dar novos sentidos aos conhecimento e novo significado para a educação básica, superando seu sentido apenas reprodutivo ou de mercado, é oportunidade que se abre hoje.

Não se trata de criar modelos novos para a educação escolar, de modo abstrato, artificialmente. Trata-se de criar condições coletivas para construir e assumir novas formas de pensar e de agir no que se refere às funções e ao trabalho escolar, com novas atitudes e perspectivas, possibilitando com isso recriar os espaços e tempos escolares, quebrar com a "hora-aula", criar alternativas para aprendizagens em coparticipação, e construir dinâmicas curriculares com o essencial dos conhecimentos importantes para a sociedade contemporânea ponderados por uma visão de futuro. O papel dos gestores e professores precisará se configurar em outros contornos e sua formação repensada.

As mobilizações na educação havidas no contexto pandêmico, as revisões e alterações feitas nas relações educacionais, as reflexões sobre as diversidades e dificuldades, as soluções experimentadas trazem possibilidade de fundamentar novas políticas educacionais e novas formas nas relações pedagógicas. Porém, mudança em cultura arraigada não é processo simples. Como sinaliza Silva Júnior $(2015$, p.132), para mudar "precisamos estar conscientes e convictos da exaustão histórica das formas de análise e dos processos de intervenção até aqui utilizados no tratamento da situação social que nos desafia, com sua inoperância e sua petrificação". E transformações "são frutos da ação organizada de pessoas e instituições que se propõem a alterar radicalmente situações dadas". Levar avante um processo de transformação na educação escolar vai requer conviçcão em novos valores e na forte necessidade de mudar. 


\section{Finalizando}

O impacto repentino das mudanças de rotinas no trabalho, no estudo, nas relações, nas necessidades, nesses tempos de isolamento social, provocou rupturas com hábitos arraigados e reflexões sobre o que é essencial e o que é supérfluo, bem como demandou exercício de paciência, desenvolvimento de atividades de modo diferente. O uso de recursos virtuais entrou em foco e suas qualidades e seus problemas estão sendo experimentados. A educação de crianças, adolescentes e jovens entrou "ao vivo" na vida dos pais ou dos responsáveis por elas. Tudo isso abalou convicções e confortos em relação aos sentidos e ao significado da formação das futuras gerações. A questão do humano em e com seu ambiente despontou com novos valores que não sabemos se terão impactos futuros ou se retornaremos aos velhos hábitos de consumir sem pensar em preservar. Sem dúvida, a angústia pela preservação das vidas marcou pontos. A educação tem tudo a ver com a preservação da vida em todos os seus aspectos, sejam sociais, ambientais, científicos, sejam culturais ou outros. É ela que pode propiciar a formação de valores de vida com base em conhecimentos, para as novas gerações. É nela que o sentido das aprendizagens é garantido e estamos diante da possibilidade de criação de nova consciência e posturas diante da vida, nas relações, na sociedade, na educação das futuras gerações. Somos chamados a superar individualismos excessivos e competitividade insana. O cuidado de si adquire sentido no cuidado de todos e no cuidado com o mundo onde vivemos. Esquecer o que estivemos sendo chamados a repensar nesse período pandêmico será um retrocesso muito indesejável para o futuro da vida. Tudo nos chama a repensar a educação fragmentária, de caráter apenas cognitivo, e, para muitos jovens e adolescentes, sem sentido, que oferecemos. Domínio de conhecimentos imbricados com valores de vida é o vetor saudável a preservar para novos tempos.

\section{Referências}

ANUÁRIO. Anuário Brasileiro da Educação Básica - 2019. São Paulo: Todos pela Educação; Editora Moderna, 2019.

BRASIL. (Constituição de 1988). Constituição da República Federativa do Brasil. Diário Oficial da União, Brasília, DF, 5 out. 1988.

Congresso Nacional. Lei 9.394 de 20 de dezembro de 1996. Estabelece as diretrizes e bases da educação nacional. Brasília, DF: Casa Civil da Presidência da República, 1996.

Ministério da Educação. Conselho Nacional de Educação. Parecer 11/2020, de 7 de julho de 2020. Orientações Educacionais para a Realização de Aulas e Atividades Pedagógicas Presenciais e Não Presenciais no contexto da Pandemia. Brasília (DF), 2020.

BRUNER, J. Actos de dignificado: más allá de la revolución cognitiva. Madrid: Alianza Editorial, 1998.

CARVALHO, J. S. Os ideais da formação humanista e o sentido da experiência escolar. Educação e Pesquisa, v.43, n.4, p.1023-34, 2017. 
CONJUVE. Juventudes e a Pandemia do Coronavirus. Relatório de Resultados, Junho de 2020. Disponível em: <https://4faldlbc-0675-4684-8ee9-031db9be0aab.filesusr. com/ugd/f0d618_4lb20ldbab994b44b00aabca4lf971bb.pdf>. Acesso em: 10 ago. 2020 .

CTE-IRB/IEDE. A Educação não pode esperar: ações para minimizar os impactos negativos à educação em razão das ações de enfrentamento ao novo coronavirus. Comitê Técnico da Educação do Instituto Rui Barbosa e Interdisciplinaridade e Evidências no Debate Educacional, junho 2020. Disponível em: <https://www.portaliede.com.br/ wp-content/uploads/2020/06/Estudo_A_Educa\%C3\%A7\%C3\%A3o_N\%C3\%A3o_ Pode_Esperar.pdf>. Acesso em: 8 ago. 2020.

INSTITUTO PENÍSULA. Relatório de Pesquisa. Sentimento e Percepção dos professores brasileiros nos diferentes estágios do Corona Virus no Brasil. Estágio Intermediário. Junho de 2020. Disponível em: <https://www.institutopeninsula.org.br/pesquisa-sentimento-e-percepcao-dos-professores-nos-diferentes-estagios-do-coronavirus-no-brasil/>. Acesso em: 3 ago. 2020.

LENT, R. O cérebro aprendiz: neuroplasticidade e educação. Rio de Janeiro: Atheneu, 2019.

MATURANA, H. Cognição, ciência e vida cotidiana. Belo Horizonte: Editora da UFMG, 2001.

MATURANA, H. R.; VARELA, F. A árvore do conbecimento: as bases biológicas da compreensão humana. São Paulo: Palas Athena, 2001.

PAULA, G. R.; BEBER, B. C.; BAGGIO, S. B.; PETRY, T. Neuropsicologia da aprendizagem. Revista Psicopedagogia, v.23, n.72, p.224-31, 2006.

PIAGET, J. A Formação do Símbolo na Criança. Imitação, jogo e sonho, imagem e representação. Rio de Janeiro: Zahar, 1971.

Fazer e compreender. São Paulo: Melhoramentos; Edusp, 1978. . A linguagem e o pensamento da criança. São Paulo: Martins Fontes, 1986.

REIMERS, F. M.; SCHLEICHER, A. Educational Opportunity during the COVID-19 Pandemic. OCDE, 2020. Disponível em: <https://globaled.gse.harvard.edu/files/ geii/files/framework_guide_v2.pdf>. Acesso em: 7 ago. 2020.

SILVA JÚNIOR, C. A. Construção de um espaço público de formação. In: SILVA JÚNIOR, C. A. et al. (Org.) Por uma revolução no campo da formação de professores. São Paulo: Editora Unesp, 2015.

UNDIME, ITAÚ SOCIAL, UNICEF, PLANO CDE E CIEB. Desafios das Secretarias Municipais de Educação, Relatório de Pesquisa, maio de 2020. Disponível em: <https://undime.org.br/noticia/16-06-2020-13-14-undime-realiza-mapeamento-da-oferta-de-atividades-educacionais-nao-presenciais-nos-municipios-durante-a-pandemia>. Acesso em: 5 ago. 2020.

VIGOTSKY, L. S. Pensamento e linguagem. São Paulo: Martins Fontes, 2003.

A formação social da mente: o desenvolvimento dos processos psicológicos superiores. São Paulo: Martins Fontes. 2007.

VILLAS BÔAS, L.; UNBEHAUM, S. (Coord.). Pesquisa: Educação escolar em tempos de pandemia na visão de professoras/es da Educação Básica. Informe n.1. São Paulo: 
Fundação Carlos Chagas, 2020. Disponível em: <https://www.fcc.org.br/fcc/educacao-pesquisa/educacao-escolar-em-tempos-de-pandemia-informe-n-1>. Acesso em: 11 ago. 2020.

WALLON, H. Les origines du caractère chez l'enfant. Les préludes du sentiment de pesonnalité. Boisvin; Paris: PUF, 1973.

A evolução psicológica da criança. São Paulo: Martins Fontes, 2007.

2008.

Do ato ao pensamento: ensaio de psicologia comparada. Petrópolis: Vozes,

WENGER, E. Communities of Practice: Learning, Meaning, and Identity. Cambridge: Cambridge University Press, 1988.

RESUMO - Neste artigo parte-se de aspectos gerais da gestão educacional em seus vários níveis, tocando na questão do isolamento social pelo evento da Covid-19 e nos impactos diversos dessa situação na educação de crianças, adolescentes e jovens. Aprofundamse especificamente questões ligadas à educação básica na situação de pandemia quanto à garantia possível das aprendizagens aos alunos, as diversidades das realidades sociais, a situação de professores e gestores, aspectos curriculares, relacionais e socioemocionais envolvidos no processo de isolamento e no retorno presencial nas escolas. Ao levantar possibilidades de vetores saudáveis no enfrentamento dessa realidade, pondera-se sobre as possibilidades de mudanças, pós-pandemia, no desenvolvimento da oferta educacional nas redes de ensino básico.

PALAVRAS-CHAVE: Covid-19, Pós-pandemia, Educação básica, Escola, Aprendizagem.

ABSTRACT - The Covid-19 pandemic and the necessity of isolation had a big impact in everyone's lives, in work and scholarship. This situation required specific educational policies but certain difficulties emerged in terms of coordinating policies at different administration levels. Remote education was a solution for most of the schools, but not for all students and teachers. They had to deal with programs and instruments that they did not know well. Preparing and giving classes online was not easy at all. Many students do not have access to the internet, to computers or cell phones, and many have no support and proper conditions at home. Some studies report problems in learning, as well as anxieties. This article discusses the return to classrooms in schools and associated problems, presents good vectors to deal with the situation and explains some ideas about a new quality in education.

KEYWORDS: Covid-19, Post-pandemic, Basic education, School, Learning.

Bernardete A. Gatti é doutora pela Universidade de Paris VII - Denis Diderot, pesquisadora consultora da Fundação Carlos Chagas e membro do Conselho Estadual de Educação e da Academia Paulista de Educação. @ - gattibe@gmail.com / https://orcid.org/0000-0002-9297-726X.

Recebido em 27.8.2020 e aceito em 15.9.2020.

I Fundação Carlos Chagas, São Paulo, Brasil. 
